\title{
Preparation and Characterization of Manganese Ferrite Aluminates
}

\author{
R. L. Dhiman, ${ }^{1}$ S. P. Taneja, ${ }^{2}$ and V. R. Reddy ${ }^{3}$ \\ ${ }^{1}$ P. G. Department of Applied Physics, S.D. College, Ambala Cantt 133 001, India \\ ${ }^{2}$ Department of Physics, Maharshi Dayanand University, Rohtak 124 001, India \\ ${ }^{3} U G C-D A E$, Consortium for Scientific Research, Khandwa Road, Indore 452 017, India
}

Correspondence should be addressed to R. L. Dhiman, roshandhiman_kuk@yahoo.co.in

Received 13 June 2008; Revised 30 September 2008; Accepted 31 December 2008

Recommended by R. N. P. Choudhary

\begin{abstract}
Aluminum doped manganese ferrites $\mathrm{MnAl}_{x} \mathrm{Fe}_{2-x} \mathrm{O}_{4}$ with $0.0 \leq x \leq 1.0$ have been prepared by the double ceramic route. The formation of mixed spinel phase has been confirmed by X-ray diffraction analysis. The unit cell parameter ' $a_{O}$ ' is found to decrease linearly with aluminum concentration due to smaller ionic radius of aluminum. The cation distributions were estimated from $\mathrm{X}$ ray diffraction intensities of various planes. The theoretical lattice parameter, X-ray density, oxygen positional parameter, ionic radii, jump length, and bonds and edges lengths of the tetrahedral (A) and octahedral (B) sites were determined. ${ }^{57} \mathrm{Fe}$ Mössbauer spectra recorded at room temperature were fitted with two sextets corresponding to $\mathrm{Fe}^{3+}$ ions at $\mathrm{A}$ - and $\mathrm{B}$-sites. In the present ferrite system, the area ratio of $\mathrm{Fe}^{3+}$ ions at the $\mathrm{A}$ - and $\mathrm{B}$-sites determined from the spectral analysis of Mössbauer spectra gives evidence that $\mathrm{Al}^{3+}$ ions replace iron ions at $\mathrm{B}$-sites. This change in the site preference reflects an abrupt change in magnetic hyperfine fields at A- and B-sites as aluminum concentration increases, which has been explained on the basis of supertransferred hyperfine field. On the basis of estimated cation distribution, it is concluded that aluminum doped manganese ferrites exhibit a 55\% normal spinel structure.
\end{abstract}

Copyright ( $) 2008$ R. L. Dhiman et al. This is an open access article distributed under the Creative Commons Attribution License, which permits unrestricted use, distribution, and reproduction in any medium, provided the original work is properly cited.

\section{Introduction}

Spinel ferrites have been the subject of great interest for the past five decades, because of their wide range of applications in transformers, inductors, choke coils, noise filters magnetic recording heads, and so forth [1]. These ferrites possessing cubic close-packed structure of oxygen ions, are described by the formula $(\mathrm{A})[\mathrm{B}]_{2} \mathrm{O}_{4}$, where $(\mathrm{A})$ and $[\mathrm{B}]$ represent tetrahedral and octahedral sites, respectively. The site occupancy is often depicted in the chemical formula as $\left(\mathrm{M}_{1-\delta} \mathrm{Fe} \delta\right)\left[\mathrm{M}_{\delta} \mathrm{Fe}_{2-\delta}\right] \mathrm{O}_{4}$, where round and square brackets denote the $\mathrm{A}$ - and $\mathrm{B}$-sites, respectively, $\mathrm{M}$ represents a metal cation, and ' $\delta$ ' is the inversion parameter. The degree of inversion ' $\delta$ ' for spinel ferrites is defined as the fraction of tetrahedral (A)-sites occupied by trivalent cations. Accordingly, for a normal spinel $\delta=0$ and for a completely inverse spinel, $\delta=1$. The magnetic and the electronic properties of such a ferrite system depend upon the type of metal cations and their distribution among the two interstitial sites, that is, A- and B-sites. Therefore, the knowledge of cation distribution is essential to understand the magnetic behavior of spinel ferrites. Manganese ferrite is early known to be a mixed inverse spinel, and the degree of inversion mainly depends upon the method of preparation. The presence of nonmagnetic ions in these spinel ferrites is found to alter their magnetic and electronic properties. The addition of metal cations such as trivalent or tetravalent influences the electronic and magnetic properties of the ferrite system [2-6]. Various studies showed that heating might change the distribution of metal cations at the A- and B-sites of $\mathrm{MnFe}_{2} \mathrm{O}_{4}$. It has been reported that by using neutron diffraction technique, the degree of inversion, that is, the distribution of the cationic ions between the tetrahedral and octahedral sites of $\mathrm{MnFe}_{2} \mathrm{O}_{4}$ prepared by usual ceramic route was determined $81 \%$ normal [7]. However, this value reduced to $33 \%$, when $\mathrm{MnFe}_{2} \mathrm{O}_{4}$ was prepared by wet chemical method [8]. Thus, the method of preparation may play a crucial role in order to obtain the desired 


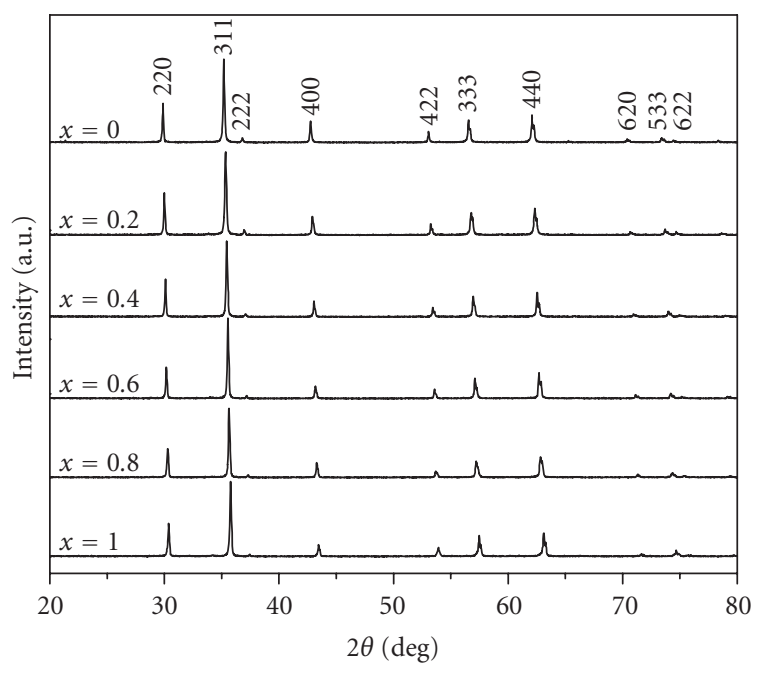

FIgURE 1: X-ray diffraction pattern of $\mathrm{MnAl}_{x} \mathrm{Fe}_{2.0-x} \mathrm{O}_{4}$ system.

electronic and magnetic properties. Extensive investigations regarding the substitution of metal cations, for example, $\mathrm{Cu}^{2+}, \mathrm{Zn}^{2+}, \mathrm{Ti}^{2+}, \mathrm{Co}^{3+}$, and $\mathrm{Ni}^{2+}$ in manganese ferrites have been reported, giving useful information about the influence of such metal cations [9-13]. However, no systematic results regarding the estimation of cation distribution on substitution of aluminum ion in $\mathrm{MnFe}_{2} \mathrm{O}_{4}$ was available. In the present studies, the cation distribution in tetrahedral and octahedral sites of aluminum substituted manganese ferrites synthesized via double ceramic route has been determined by X-ray diffraction and Mössbauer spectroscopic measurements.

\section{Experimental}

Samples of the mixed spinel ferrites $\mathrm{MnAl}_{x} \mathrm{Fe}_{2.0-x} \mathrm{O}_{4}$ for $x=0.0,0.2,0.4,0.6,0.8$, and 1.0 were synthesized by usual double ceramic processing technique. The starting materials were high-purity analytical reagent grade oxides, $\mathrm{Fe}_{2} \mathrm{O}_{3}$, $\mathrm{MnO}$, and $\mathrm{Al}_{2} \mathrm{O}_{3}$. The required compositions were weighed and mixed in a mortar and pestle. The mixed powders were presintered at $1000^{\circ} \mathrm{C}$ for 10 hours in the air and allowed to cool to room temperature at the rate of about $2^{\circ} \mathrm{C} / \mathrm{min}$. In the final sintering process, the samples were placed in a furnace at $1300^{\circ} \mathrm{C}$ for 10 hours in the air and then cooled slowly to room temperature at the rate of $2^{\circ} \mathrm{C} / \mathrm{min}$. The finally sintered materials were well grounded. To ensure their single-phase nature, the powder X-ray diffraction studies were made on Regaku X-ray diffractometer by using $\mathrm{Cu}$ $\mathrm{K}_{\alpha}$ radiation of wave length $1.54060 \AA .{ }^{57} \mathrm{Fe}$ Mössbauer absorption spectra were recorded in transmission geometry at room temperature using a multichannel analyzer with a drive in constant acceleration mode. $\mathrm{A}{ }^{57} \mathrm{Co}(\mathrm{Rh})$ source with initial activity of $20 \mathrm{mCi}$ was used. The spectrometer was periodically calibrated using a natural iron foil as a standard.

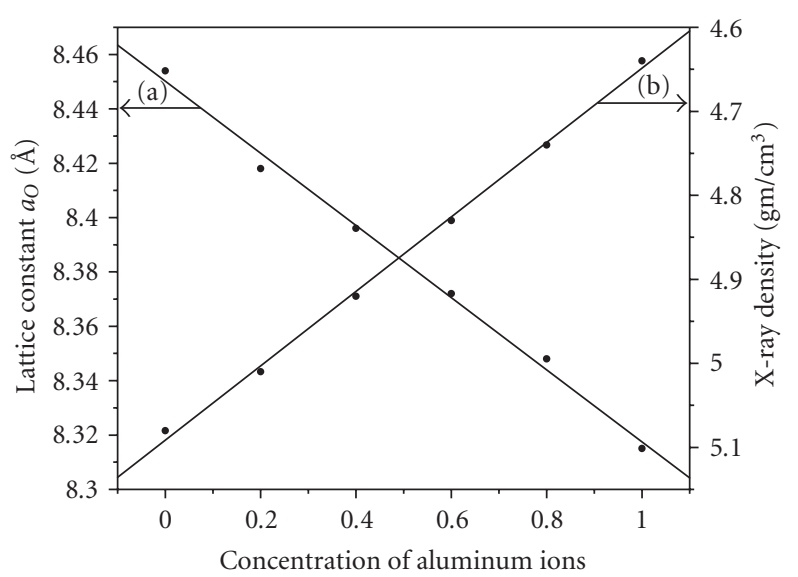

FIGURE 2: Variation of (a) lattice constant and (b) X-ray density with aluminum ions concentration.

\section{Results and Discussion}

\subsection{X-Ray Diffraction Analysis}

The X-ray diffraction patterns of mixed spinel ferrites $\left(\mathrm{MnAl}_{x} \mathrm{Fe}_{2.0-x} \mathrm{O}_{4}\right.$ for $x=0.0,0.2,0.4,0.6,0.8$, and 1.0) are shown in Figure 1.

The positions of diffraction peaks from various planes were identified using JCPDS file no. 74-2403. It is evident from Figure 1 that each ferrite sample exhibits single-phase cubic spinel structure with Fd-3m (227) space group. The value of the lattice constant ' $a_{O}$ ' for all the samples was determined from the position of principal (311) peak using

$$
a_{O}=d_{h k l} \sqrt{h^{2}+k^{2}+l^{2}},
$$

where $h, k$, and $l$ are the miller indices.

The observed values of lattice constant ' $a_{O}$ ' listed in Table 1 are slightly smaller than the JCPDS table value of $8.518 \AA$. The lattice constant ' $a_{O}$ ' is found to decrease linearly with aluminum concentration $(x)$ as shown in Figure 2(a), thereby obeying Vegard's law [14].

The decrease in lattice constant is attributed to the fact that the Pauling ionic radius of $\mathrm{Al}^{3+}(0.50 \AA)$ is smaller than that of $\mathrm{Fe}^{3+}(0.64 \AA)$, which causes the shrinking in the unit cell dimensions. The decrease in ' $a_{O}$ ' and the shift of reflections toward higher angle with the increasing aluminum concentration $(x)$ show that aluminum atoms have been incorporated into the spinel structure [15]. [16]

The X-ray density ' $d_{x}$ ' was calculated using the formula

$$
d_{x}=\frac{8 M}{N a_{O}^{3}},
$$

where ' $M$ ' is the molecular weight, ' $N$ ' is the Avogadro's number, and ' $a_{O}$ ' is the lattice constant of the spinel ferrite. The calculated values of X-ray density are listed in Table 1 . The X-ray density decreases with increasing aluminum concentration $(x)$, as shown in Figure 2(b). The decrease in $\mathrm{X}$-ray density is due to the decrease in mass, which overtakes the decrease in volume of the unit cell. 
TABLE 1: Lattice constant, density, and volume for $\mathrm{MnAl}_{x} \mathrm{Fe}_{2.0-x} \mathrm{O}_{4}$ system.

\begin{tabular}{lcccc}
\hline Composition $(x)$ & \multicolumn{2}{c}{ Lattice constant } & $\begin{array}{c}\text { Volume } \\
\AA^{3}\end{array}$ & $\begin{array}{c}\text { X-ray density } \\
\left(d_{x} \pm 0.002\right) \mathrm{gm} / \mathrm{cm}^{3}\end{array}$ \\
\hline 0.0 & 8.454 & $\left(a_{t} \pm 0.002\right) \AA$ & 604.23 & 5.07 \\
0.2 & 8.417 & 8.504 & 596.46 & 5.01 \\
0.4 & 8.396 & 8.455 & 592.05 & 4.92 \\
0.6 & 8.372 & 8.407 & 586.84 & 4.83 \\
0.8 & 8.348 & 8.358 & 581.96 & 4.74 \\
1.0 & 8.315 & 8.310 & 574.89 & 4.64 \\
\hline
\end{tabular}

TABLE 2: Cation distribution data calculated from XRD pattern of the $\mathrm{MnAl}_{x} \mathrm{Fe}_{2.0-x} \mathrm{O}_{4}$ system.

\begin{tabular}{|c|c|c|c|c|c|c|}
\hline \multirow[b]{3}{*}{ Composition } & \multicolumn{5}{|c|}{ X-ray intensity } & \multirow[b]{3}{*}{$\mathrm{Fe}^{3+}(\mathrm{B}) / \mathrm{Fe}^{3+}(\mathrm{A})$} \\
\hline & \multicolumn{2}{|c|}{$I_{220} / I_{440}$} & \multicolumn{2}{|c|}{$I_{400} / I_{440}$} & \multirow[b]{2}{*}{ Cation distribution } & \\
\hline & Exp. & Cal. & Exp. & Cal. & & \\
\hline $\mathrm{MnFe}_{2.0} \mathrm{O}_{4}$ & 1.0247 & 1.1796 & 0.9622 & 0.7643 & $\left(\mathrm{Fe}_{0.446} \mathrm{Mn}_{0.554}\right)^{\mathrm{A}}\left[\mathrm{Fe}_{1.554} \mathrm{Mn}_{0446}\right]^{\mathrm{B}}$ & 3.48 \\
\hline $\mathrm{MnAl}_{0.2} \mathrm{Fe}_{1.8} \mathrm{O}_{4}$ & 1.0348 & 1.2807 & 0.9624 & 0.6902 & $\left(\mathrm{Fe}_{0.446} \mathrm{Mn}_{0.554}\right)^{\mathrm{A}}\left[\mathrm{Fe}_{1.354} \mathrm{Mn}_{0.446} \mathrm{AL}_{0.2}\right]^{\mathrm{B}}$ & 3.03 \\
\hline $\mathrm{MnAl}_{0.4} \mathrm{Fe}_{1.6} \mathrm{O}_{4}$ & 1.0565 & 1.3772 & 0.9433 & 0.6483 & $\left(\mathrm{Fe}_{0.446} \mathrm{Mn}_{0.554}\right)^{\mathrm{A}}\left[\mathrm{Fe}_{1.254} \mathrm{Mn}_{0.446} \mathrm{AL}_{0.4}\right]^{\mathrm{B}}$ & 2.58 \\
\hline $\mathrm{MnAl}_{0.6} \mathrm{Fe}_{1.4} \mathrm{O}_{4}$ & 1.0579 & 1.4772 & 0.9257 & 0.6112 & $\left(\mathrm{Fe}_{0.446} \mathrm{Mn}_{0.554}\right)^{\mathrm{A}}\left[\mathrm{Fe}_{0.954} \mathrm{Mn}_{0.446} \mathrm{AL}_{0.6}\right]^{\mathrm{B}}$ & 2.13 \\
\hline $\mathrm{MnAl}_{0.8} \mathrm{Fe}_{1.2} \mathrm{O}_{4}$ & 1.0780 & 1.5020 & 0.8414 & 0.5711 & $\left(\mathrm{Fe}_{0.446} \mathrm{Mn}_{0.554}\right)^{\mathrm{A}}\left[\mathrm{Fe}_{0.754} \mathrm{Mn}_{0.446} \mathrm{AL}_{0.8}\right]^{\mathrm{B}}$ & 1.69 \\
\hline $\mathrm{MnAl}_{1.0} \mathrm{Fe}_{1.0} \mathrm{O}_{4}$ & 1.0910 & 1.5700 & 0.5907 & 0.5256 & $\left(\mathrm{Fe}_{0.446} \mathrm{Mn}_{0.554}\right)^{\mathrm{A}}\left[\mathrm{Fe}_{0.554} \mathrm{Mn}_{0.446} \mathrm{AL}_{1.0}\right]^{\mathrm{B}}$ & 1.24 \\
\hline
\end{tabular}

The cation distribution in the various spinel ferrite systems has been estimated from X-ray diffraction [5, 6], Mössbauer's effect [17, 18], and magnetization measurements $[19,20]$. It has been reported $[21,22]$ that the best information in estimation of cation distribution can be achieved by comparing the experimental and theoretical intensity ratios for reflections (220), (422), and (400). However, the intensities of (220), (422), and (400) planes are more sensitive to cations on A- and B-sites [23, 24]. The X-ray diffraction intensity of the respective planes was calculated using the formula [25]

$$
I_{h k l}=\left|F_{h k l}\right|^{2} \cdot P \cdot L_{P}
$$

where $I_{h k l}$ is the relative integral intensity; $F_{h k l}$ is the structure factor; $P$ is the multiplicity factor; $L p$ is the Lorentz factor. The structural factors were calculated by using the equation suggested by Porta and Furuhashi et al. [26, 27]. The multiplicity factor and the Lorentz factors were taken from the literature [16]. The ionic scattering factor reported in the international tables for X-ray crystallography [28] is used for the calculation of structural factor. It is well established that the intensity ratios $I_{220} / I_{440}$ and $I_{400} / I_{440}$ are considered to be sensitive to cation distribution [29]. Therefore in the present ferrite system, intensity ratios of these planes have been used in estimation of cation distribution. The intensity ratios of these planes were calculated for various cation distributions using the following expression suggested by Bertaut [21]:

$$
\left(\frac{I_{h k l}}{I_{h^{I} k^{l} l^{l}}}\right)_{\mathrm{obs}}=\left(\frac{I_{h k l}}{I_{h^{I} k^{I} l^{l}}}\right)_{\mathrm{cal}} .
$$

For all the samples, the calculated values, those closest to the experimental observed values, are given in Table 2.
The theoretical lattice constant ' $a_{t}$ ' for all composition was calculated on the basis of estimated cation distribution by using the relation [30]

$$
a_{t}=\frac{8}{3 \sqrt{3}}\left(r_{\mathrm{A}}+r_{\mathrm{O}}\right)+\sqrt{3}\left(r_{\mathrm{B}}+r_{\mathrm{O}}\right)
$$

where $r_{\mathrm{A}}$ and $r_{\mathrm{B}}$ are the radii of the $\mathrm{A}$ - and the $\mathrm{B}$-sites, respectively, and $r_{\mathrm{O}}$ is the radius of the oxygen ion $\mathrm{O}^{2-}$ $(1.48 \AA)$. The calculated values ' $a$ ' are nearly equal to the experimental observed value ' $a_{O}$ ' which confirms the estimated cation distribution (see Table 2). The site radii $r_{\mathrm{A}}$ and $r_{\mathrm{B}}$ used above were determined using the following:

$$
\begin{aligned}
& r_{\mathrm{A}}=0.446 r_{\mathrm{tet}} \mathrm{Fe}^{3+}+0.554 r_{\mathrm{tet}} \mathrm{Mn}^{2+}, \\
& r_{\mathrm{B}}=(1.554-x) r_{\mathrm{oct}} \mathrm{Fe}^{3+}+0.446 r_{\mathrm{oct}} \mathrm{Mn}^{2+}+x r_{\mathrm{oct}} \mathrm{Al}^{3+} .
\end{aligned}
$$

The calculated values of $r_{\mathrm{A}}$ and $r_{\mathrm{B}}$ are listed in Table 3 . The value of $r_{\mathrm{A}}$ decreases slowly; however the value of $r_{\mathrm{B}}$ decreases noticeably with increasing aluminum concentration. This is due to the replacement of larger ionic radii $\left(\mathrm{Fe}^{3+}\right)$ with smaller ionic radii $\left(\mathrm{Al}^{3+}\right)$ and their distribution amongst the $\mathrm{A}$ - and $\mathrm{B}$-sites. The value of the oxygen positional parameter ' $u$ ' was calculated by using the following relation:

$$
r_{\mathrm{A}}=a_{O} \sqrt{3}(u-0.25)-r_{O}
$$

The determined values of ' $u$ ' are listed in Table 3. The values of the tetrahedral $\left(d_{\mathrm{AL}}\right)$, octahedral bond length $\left(d_{\mathrm{B} L}\right)$, tetrahedral edge length $\left(d_{\mathrm{AE}}\right)$, and shared $\left(d_{\mathrm{B} E}\right)$ and unshared octahedral edge lengths $\left(d_{\mathrm{BEU}}\right)$ were calculated by using 
TABLE 3: X-ray parameters (error bar $\pm 0.002 \AA)$ : tetrahedral and octahedral bond lengths $\left(d_{\mathrm{A} L}\right.$ and $\left.d_{\mathrm{B} L}\right)$ and jump lengths $\left(L_{\mathrm{A}}\right.$ and $\left.L_{\mathrm{B}}\right)$, tetrahedral edge $d_{\mathrm{AE}}$, and shared and unshared octahedral edges $\left(d_{\mathrm{BE}}\right.$ and $\left.d_{\mathrm{BEU}}\right)$.

\begin{tabular}{lcccccccccc}
\hline Composition $(x)$ & $d_{\mathrm{AL}}(\AA)$ & $d_{\mathrm{BL}}(\AA)$ & $d_{\mathrm{A} E}(\AA)$ & $d_{\mathrm{B} E}(\AA)$ & $d_{\mathrm{B} E U}(\AA)$ & $L_{\mathrm{A}}(\AA)$ & $L_{\mathrm{B}}(\AA)$ & $r_{\mathrm{A}}(\AA)$ & $r_{\mathrm{B}}(\AA)$ & $u(\AA)$ \\
\hline 0.0 & 2.2477 & 1.9031 & 3.6704 & 2.3075 & 3.0282 & 3.6607 & 2.9889 & 0.7286 & 1.3514 & 0.4035 \\
0.2 & 2.2496 & 1.8922 & 3.6737 & 2.2785 & 3.0183 & 3.6436 & 2.9750 & 0.7286 & 1.3253 & 0.4043 \\
0.4 & 2.2499 & 1.8858 & 3.7453 & 2.2633 & 3.0100 & 3.6359 & 2.9687 & 0.7286 & 1.2993 & 0.4047 \\
0.6 & 2.2491 & 1.8776 & 3.6727 & 2.2472 & 3.0023 & 3.6252 & 2.9600 & 0.7286 & 1.2732 & 0.4051 \\
0.8 & 2.2498 & 1.8685 & 3.6739 & 2.2289 & 2.9953 & 3.6147 & 2.9514 & 0.7286 & 1.2473 & 0.4056 \\
1.0 & 2.2482 & 1.8592 & 3.6712 & 2.2083 & 2.9853 & 3.6005 & 2.9397 & 0.7286 & 1.2213 & 0.4061 \\
\hline
\end{tabular}

the experimental values of lattice constant ' $a_{O}$ ' and oxygen positional parameter ' $u$ ' from the following [30, 31]:

$$
\begin{aligned}
d_{\mathrm{A} L} & =a_{O} \sqrt{3}(u-0.25), \\
d_{\mathrm{B} L} & =a_{O} \sqrt{\left(3 u^{2}-\frac{11}{4} u+\frac{43}{64}\right)}, \\
d_{\mathrm{A} E} & =a_{O} \sqrt{2}(2 u-0.5), \\
d_{\mathrm{B} E} & =a_{O} \sqrt{2}(1-2 u), \\
d_{\mathrm{B} E U} & =a_{O} \sqrt{\left(4 u^{2}-3 u+\frac{11}{16}\right)} .
\end{aligned}
$$

Various calculated X-ray parameters are given in Table 3. It is observed that $d_{\mathrm{A} L}, d_{\mathrm{B} L}, d_{\mathrm{A} E}, d_{\mathrm{B} E}$, and $d_{\mathrm{B} E U}$ decrease with increasing aluminum concentration $(x)$. This is due to the substitution process, that is, replacement of larger ionic radii $\left(\mathrm{Fe}^{3+}\right)$ by smaller ionic radii $\left(\mathrm{Al}^{3+}\right)$ and their distribution among the A- and B-sites. These results are in consistent with the reported data [32]. It has been reported that the jump length ' $L$ ' (the distance between the magnetic ions) of electrons influences the physical properties of the ferrite system [33]. Electrons those are hopping between B- and Asites are less probable compared to that between B- and Bsites, because the distance between the two metal ions placed in B-sites is smaller than if they were placed one in B-sites and the other in A-sites [34]. ' $L$ ' of the A- and B-sites is determined from the following relations [35]:

$$
\begin{aligned}
& L_{\mathrm{A}}=a_{O} \frac{\sqrt{3}}{4}, \\
& L_{\mathrm{B}}=a_{O} \frac{\sqrt{2}}{4} .
\end{aligned}
$$

It is observed that ' $L$ ' of A- and B-sites decreases with increasing aluminum concentration $(x)$ as shown in Figure 3.

The decrease in jump length is due to the decrease in the distance between the magnetic ions by the substitution of smaller $\mathrm{Al}^{3+}$ ions at the $\mathrm{B}$-sites and is similar to those reported earlier $[4,32]$.

\subsection{Mössbauer Analysis}

${ }^{57} \mathrm{Fe}$ Mössbauer absorption spectra of mixed spinel ferrite system $\mathrm{MnAl}_{x} \mathrm{Fe}_{2.0-x} \mathrm{O}_{4}$ for $x=0.0,0.2,0.4,0.6,0.8$, and 1.0 recorded at room temperature are displayed in

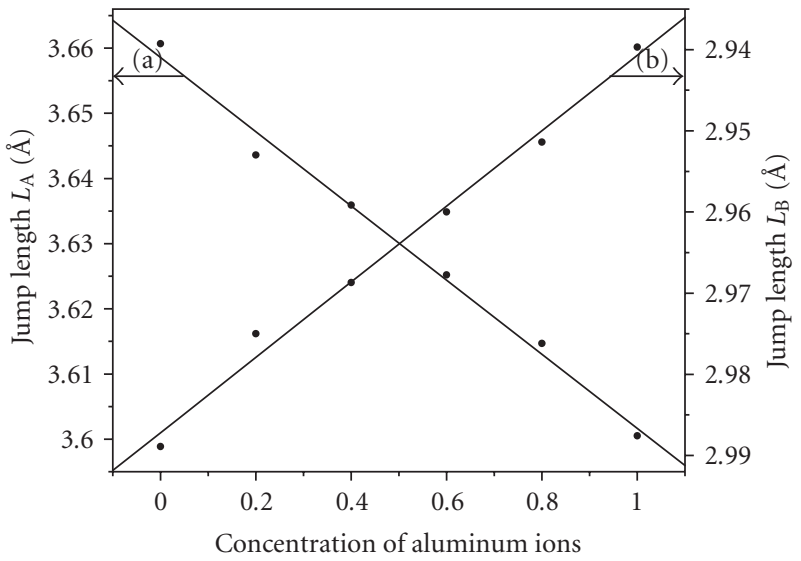

FIGURE 3: Variation of jump length ' $L$ ' with aluminum ions concentration.

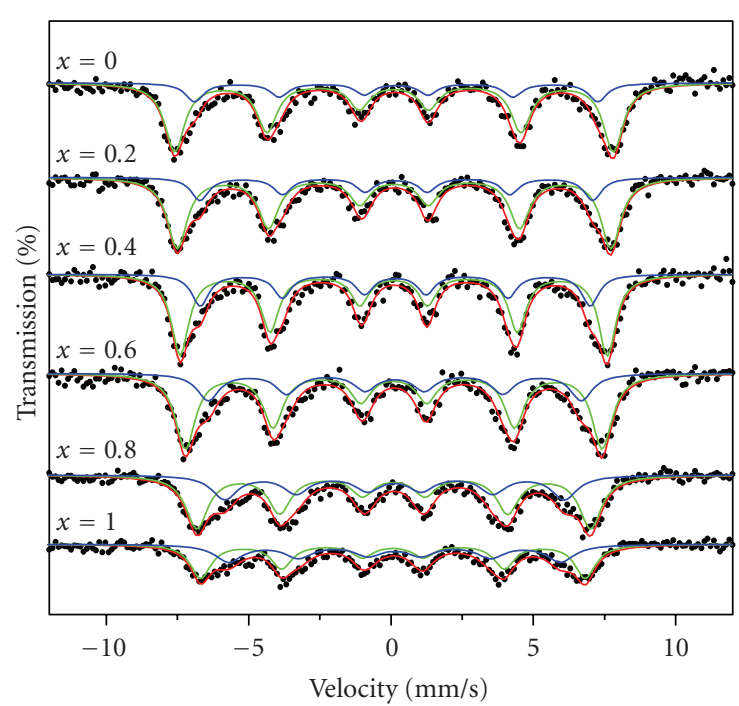

Figure 4: Room temperature Mössbauer absorption spectra of $\mathrm{MnAl}_{x} \mathrm{Fe}_{2.0-x} \mathrm{O}_{4}$, for $x=0.0,0.2,0.4,0.6,0.8$, and 1.0.

Figure 4. The experimental data were fitted using least square-fitting (NORMOS/SITE) program [36]. Each spectrum exhibits a superposition of two Zeeman sextets, one sextet corresponding to a higher magnetic field is attributed to $\mathrm{Fe}^{3+}$ ions on the B-site, and the other sextet corresponding to lower magnetic field is attributed to $\mathrm{Fe}^{3+}$ 
TABLE 4: Room temperature Mössbauer's effect parameters for $\mathrm{MnAl}_{x} \mathrm{Fe}_{2.0-} \mathrm{O}_{4}$ system as a function of $x$.

\begin{tabular}{|c|c|c|c|c|c|c|}
\hline Composition $(x)$ & site & $\begin{array}{l}\text { Isomer shift }^{*} \\
(\delta \pm 0.01) \mathrm{mm} / \mathrm{s}\end{array}$ & $\begin{array}{l}\text { Quadrupole splitting } \\
(\Delta \pm 0.01) \mathrm{mm} / \mathrm{s}\end{array}$ & $\begin{array}{c}H_{\mathrm{hfs}} \\
( \pm 2.0 \mathrm{~T})\end{array}$ & Area $(\%)$ & $\mathrm{Fe}^{3+}(\mathrm{B}) / \mathrm{Fe}^{3+}(\mathrm{A})$ \\
\hline \multirow[t]{2}{*}{0.0} & B & 0.18 & 0.00 & 47.71 & 77.74 & 3.49 \\
\hline & A & 0.11 & 0.00 & 43.48 & 22.26 & \\
\hline \multirow[t]{2}{*}{0.2} & B & 0.17 & 0.00 & 47.16 & 75.15 & 3.02 \\
\hline & A & 0.11 & 0.00 & 42.71 & 24.85 & \\
\hline \multirow[t]{2}{*}{0.4} & B & 0.16 & 0.00 & 46.46 & 72.01 & 2.57 \\
\hline & A & 0.10 & 0.00 & 42.41 & 27.99 & \\
\hline \multirow[t]{2}{*}{0.6} & B & 0.13 & 0.00 & 45.34 & 68.92 & 2.20 \\
\hline & A & 0.10 & 0.00 & 40.58 & 31.08 & \\
\hline \multirow[t]{2}{*}{0.8} & B & 0.12 & 0.00 & 42.82 & 62.88 & 1.69 \\
\hline & A & 0.10 & 0.00 & 36.94 & 37.12 & \\
\hline \multirow[t]{2}{*}{1.0} & B & 0.11 & 0.00 & 41.80 & 55.90 & 1.26 \\
\hline & A & 0.10 & 0.00 & 36.54 & 44.10 & \\
\hline
\end{tabular}

* Isomer shift given relative to $\alpha$-Fe.

ions on the A-site. The refined values of the hyperfine parameters computed from the Mössbauer spectra are listed in Table 4. In the present ferrite system, it is observed that on increasing $\mathrm{Al}^{3+}$ ions concentration, the values of isomer shift $(\delta)$ of tetrahedral A-sites show almost negligible change, indicating that aluminum ions do not enter in Asites. The isomer shift of B-sites is greater than A-site and is in agreement with the reported data [11]. Furthermore, the observed values of isomer shift $(\delta)$ are significantly less than the expected value, $0.5 \mathrm{~mm} / \mathrm{s}$ for the $\mathrm{Fe}^{2+}$ ions [20]. Hence, the presence of $\mathrm{Fe}^{2+}$ ions in the present ferrite system is ruled out. Thus the electron exchange interaction $\left(\mathrm{Fe}^{2+} \leftrightarrow \mathrm{Fe}^{3+}+\mathrm{e}^{-}\right)$does not occur, and hence the oxidation state of $\mathrm{Fe}^{3+}$ remains unchanged during synthesis process. The hyperfine field $H_{\mathrm{hfs}}$ values at $\mathrm{B}$ - and A-sites show a gradual decrease with increasing $\mathrm{Al}^{3+}$ concentration $(x)$. This can be explained on the basis of supertransferred hyperfine field at the central cation that originates from the magnetic moments of the nearest-neighbor cations, that is, from the intra-sublattice contributions $h_{\mathrm{AA}}$ and $h_{\mathrm{BB}}$ and the inter-sublattice contributions $h_{\mathrm{AB}}$ and $h_{\mathrm{BA}}$. In the present ferrite system, the intra-sublattice contributions $h_{\mathrm{AA}}$ and $h_{\mathrm{BB}}$ are predominant. It has been reported that the intensities corresponding to (200) and (422) reflections are most sensitive to cations on A-sites [23, 24]. The X-ray diffraction patterns of the present ferrite system indicate that the intensity of (220) and (422) reflections remains almost constant as compared to (311) reflection, suggesting that $\mathrm{Al}^{3+}$ ions do not enter in the A-sites. The value of isomer shift $(\delta)$ of A-sites remains invariant on substitution of aluminum ions suggesting that $\mathrm{Al}^{3+}$ ions do not replace $\mathrm{Fe}^{3+}$ ions from A-sites. The introduction of $\mathrm{Al}^{3+}$ ions that replaces $\mathrm{Fe}^{3+}$ ions from $\mathrm{B}$-sites decreases intra-sublattice contributions, which in turn decreases the hyperfine field $H_{\text {hfs }}$ values. As nonmagnetic $\mathrm{Al}^{3+}$ ions replace $\mathrm{Fe}^{3+}$ ions, the correct amount of $\mathrm{Fe}^{3+}$ ions occupying $\mathrm{A}$ - and $\mathrm{B}$-sites is estimated by determining the area under the Mössbauer absorption spectra through the least square fitting program. The $\mathrm{Fe}^{3+}(\mathrm{B}) / \mathrm{Fe}^{3+}(\mathrm{A})$ ratio obtained from the Mössbauer spectra is in good agreement with those calculated from Xray intensities. It is observed that this ratio decreases with increasing aluminum concentration $(x)$ suggesting a decrease in ferrimagnetic behavior.

\section{Conclusion}

Aluminum substituted manganese ferrites $\mathrm{MnAl}_{x} \mathrm{Fe}_{2.0-} \mathrm{O}_{4}$ for $x=0.0,0.2,0.4,0.6,0.8$, and 1.0 have been prepared by double ceramic processing technique. The unit cell parameter decreases linearly with the increase of aluminum concentration $(x)$ due to its small ionic radius. The cation distribution estimated from X-ray intensity ratios has been verified by comparing the theoretical and experimental lattice parameters. It is observed that the correct amount of $\mathrm{Fe}^{3+}$ ions occupying B- and A-sites obtained from Mössbauer spectra is in good agreement with those calculated from X-ray intensity calculations. The hyperfine magnetic field obtained from the Mössbauer absorption spectra decreases with increasing aluminum concentration suggesting the decrease in ferrimagnetic behavior and has been explained on the basis of supertransferred hyperfine field mechanism. The X-ray determined parameters, for example, lattice constant, X-ray density, ionic radius, bond length, jump length of the A- and B-sites, oxygen positional parameter, A-site edge length, and shared and unshared B-site edge lengths were determined and found affected by $\mathrm{Al}^{3+}$ ions substitution. On the basis of estimated cation distribution, it is concluded that the present ferrite system exhibits a 55\% normal spinel structure.

\section{Acknowledgments}

One of the authors (R. L. Dhiman) is grateful to Dr. Alok Banerjee and Dr. R. J. Chaudhary, Scientists, UGC-DAE, Consortium for Scientific Research, University Campus, Khandwa Road, Indore (MP), India, for providing experimental facilities. 


\section{References}

[1] H. Igarashi and M. Okazaki, "Effects of porosity and grain size on the magnetic properties of NiZn ferrite," Journal of the American Ceramic Society, vol. 60, no. 1-2, pp. 51-54, 1977.

[2] R. Lal, Suman, N. D. Sharma, S. P. Taneja, and V. R. Reddy, "Structural and magnetic properties of zinc ferrite aluminates," Indian Journal of Pure and Applied Physics, vol. 45, no. 3, pp. 231-237, 2007.

[3] S. Singhal, S. K. Barthwal, and K. Chandra, "Structural, magnetic and Mössbauer spectral studies of nanosize aluminum substituted nickel zinc ferrites," Journal of Magnetism and Magnetic Materials, vol. 296, no. 2, pp. 94-103, 2006.

[4] A. A. Pandit, A. R. Shitre, D. R. Shengule, and K. M. Jadhav, "Magnetic and dielectric properties of $\mathrm{Mg}_{1+x} \mathrm{Mn}_{x} \mathrm{Fe}_{2-2 x} \mathrm{O}_{4}$ ferrite system," Journal of Materials Science, vol. 40, no. 2, pp. 423-428, 2005.

[5] S. Singhal, J. Singh, S. K. Barthwal, and K. Chandra, "Preparation and characterization of nanosize nickel-substituted cobalt ferrites $\left(\mathrm{Co}_{1-x} \mathrm{Ni}_{x} \mathrm{Fe}_{2} \mathrm{O}_{4}\right)$," Journal of Solid State Chemistry, vol. 178, no. 10, pp. 3183-3189, 2005.

[6] R. Justin Joseyphus, A. Narayanasamy, K. Shinoda, B. Jeyadevan, and K. Tohji, "Synthesis and magnetic properties of the size-controlled $\mathrm{Mn}-\mathrm{Zn}$ ferrite nanoparticles by oxidation method," Journal of Physics and Chemistry of Solids, vol. 67, no. 7, pp. 1510-1517, 2006.

[7] J. M. Hastings and L. M. Corliss, "Neutron diffraction study of manganese ferrite," Physical Review, vol. 104, no. 2, pp. 328331, 1956.

[8] J. Sakurai and T. Shinjo, "Neutron diffraction of manganese ferrite prepared from aqueous solution," Journal of the Physical Society of Japan, vol. 23, no. 6, p. 1426, 1967.

[9] M. U. Rana, M. U. Islam, and T. Abas, "Cation distribution in Cu-substituted manganese ferrites," Materials Letters, vol. 41, no. 2, pp. 52-56, 1999.

[10] J. Feng, L.-Q. Guo, X. Xu, S.-Y. Qi, and M.-L. Zhang, "Hydrothermal synthesis and characterization of $\mathrm{Mn}_{1-x} \mathrm{Zn}_{x} \mathrm{Fe}_{2} \mathrm{O}_{4}$ nanoparticles," Physica B, vol. 394, no. 1, pp. 100-103, 2007.

[11] S. Mishra, T. K. Kundu, K. C. Barick, D. Bahadur, and D. Chakravorty, "Preparation of nanocrystalline $\mathrm{MnFe}_{2} \mathrm{O}_{4}$ by doping with $\mathrm{Ti}^{4+}$ ions using solid-state reaction route," Journal of Magnetism and Magnetic Materials, vol. 307, no. 2, pp. 222226, 2006.

[12] M. K. Fayek, F. M. Sayed Ahmed, S. S. Ata-Allah, M. K. Elnimer, and M. F. Mostafa, "Crystal, magnetic and electric behaviour of $\mathrm{CoMn}_{x} \mathrm{Fe}_{2-x} \mathrm{O}_{4}$ cubic ferrites," Journal of Materials Science, vol. 27, no. 17, pp. 4813-4817, 1992.

[13] Q.-M. Wei, J.-B. Li, and Y.-J. Chen, "Cation distribution and infrared properties of $\mathrm{Ni}_{x} \mathrm{Mn}_{1-x} \mathrm{Fe}_{2} \mathrm{O}_{4}$ ferrites," Journal of Materials Science, vol. 36, no. 21, pp. 5115-5118, 2001.

[14] C. G. Whinfrey, D. W. Eckart, and A. Tauber, "Preparation and X-ray diffraction data for some rare earth stannates," Journal of the American Chemical Society, vol. 82, no. 11, pp. 2695-2697, 1960.

[15] J. A. Toledo, M. A. Valenzuela, P. Bosch, et al., "Effect of $\mathrm{AI}^{3+}$ introduction into hydrothermally prepared $\mathrm{ZnFe}_{2} \mathrm{O}_{4}$," Applied Catalysis A, vol. 198, no. 1-2, pp. 235-245, 2000.

[16] B. D. Cullity, Elements of X-Ray Diffraction, Addison-Wesley, Reading, Mass, USA, 1959.

[17] S. S. Ata-Allah and M. Kaiser, "Cation distribution, hyperfine parameters and conduction mechanism in the ferrimagnetic system $\mathrm{Cu}_{0.5} \mathrm{Co}_{0.5} \mathrm{Ga}_{x} \mathrm{Fe}_{2-x} \mathrm{O}_{4}$," Physica Status Solidi B, vol. 242, no. 6, pp. 1324-1335, 2005.

[18] A. Rais, A. M. Gismelseed, and I. A. Al-Omari, "Cation distribution and magnetic properties of nickel-chromium ferrites $\mathrm{NiCr}_{x} \mathrm{Fe}_{2-x} \mathrm{O}_{4}(0 \leq x \leq 1.4)$," Physica Status Solidi $B$, vol. 242, no. 7, pp. 1497-1503, 2005.

[19] S. A. Jadhav, "Magnetic properties of Zn-substituted Li-Cu ferrites," Journal of Magnetism and Magnetic Materials, vol. 224, no. 2, pp. 167-172, 2001.

[20] K. P. Thummer, M. C. Chhantbar, K. B. Modi, G. J. Baldha, and H. H. Joshi, "Localized canted spin behaviour in $\mathrm{Zn}_{x} \mathrm{Mg}_{1.5-x} \mathrm{Mn}_{0.5} \mathrm{FeO}_{4}$ spinel ferrite system," Journal of Magnetism and Magnetic Materials, vol. 280, no. 1, pp. 23-30, 2004.

[21] E. F. Bertaut, "Etude de la nature des ferrites spinelles," Comptes Rendus Hebdomadaires des Séances de l'Academie des Sciences, vol. 230, pp. 213-215, 1950.

[22] L. Weil, E. F. Bertaut, and L. Bochirol, "Propriétés magnétiques et structure de la phase quadratique du ferrite de cuivre," Journal de Physique et Le Radium, vol. 11, no. 5, pp. 208-212, 1950.

[23] E. Eoiska and W. Woiski, "The evidence of $\mathrm{Cd}_{x}{ }^{2+} \mathrm{Fe}_{1-x}{ }^{3+}\left[\mathrm{Ni}_{1-x}{ }^{2+} \mathrm{Fe}_{1+x}{ }^{3+}\right] \mathrm{O}_{4}$ cation distribution based on X-ray and Mössbauer data," Physica Status Solidi A, vol. 132, no. 1, pp. K51-K56, 1992.

[24] B. P. Ladgaonkar and A. S. Vaingankar, "X-ray diffraction investigation of cation distribution in $\mathrm{Cd}_{x} \mathrm{Cu}_{1-x} \mathrm{Fe}_{2} \mathrm{O}_{4}$ ferrite system," Materials Chemistry and Physics, vol. 56, no. 3, pp. 280-283, 1998.

[25] M. G. Buerger, Crystal Structure Analysis, John Wiley \& Sons, New York, NY, USA, 1960.

[26] P. Porta, F. S. Stone, and R. G. Turner, "The distribution of nickel ions among octahedral and tetrahedral sites in $\mathrm{NiAl}_{2} \mathrm{O}_{4}-\mathrm{MgAl}_{2} \mathrm{O}_{4}$ solid solutions," Journal of Solid State Chemistry, vol. 11, no. 2, pp. 135-147, 1974.

[27] H. Furuhashi, M. Inagaki, and S. Naka, "Determination of cation distribution in spinels by X-ray diffraction method," Journal of Inorganic and Nuclear Chemistry, vol. 35, no. 8, pp. 3009-3014, 1973.

[28] C. H. MacGillavry, G. D. Rieck, and K. Lonsdale, Physical and Chemical Tables, International Tables for X-Ray Crystallography, Volume III, Kynoch Press, Birmingham, UK, 1968.

[29] H. Ohnishi and T. Teranishi, "Crystal distortion in copper ferrite-chromite series," Journal of the Physical Society of Japan, vol. 16, no. 1, pp. 35-43, 1961.

[30] A. A. Yousif, M. E. Elzain, S. A. Mazen, H. H. Sutherland, M. H. Abdalla, and S. F. Masour, "Mössbauer and X-ray diffraction investigation of Li-Ti ferrites," Journal of Physics: Condensed Matter, vol. 6, no. 29, pp. 5717-5724, 1994.

[31] M. A. Amer, " ${ }^{57} F e$ Mössbauer, infrared and X-ray studies of the system $\mathrm{Zn}_{1-x} \mathrm{Cu}_{x} \mathrm{Cr}_{0.8} \mathrm{Fe}_{1.2} \mathrm{O}_{4}$," Physica Status Solidi A, vol. 181, no. 2, pp. 539-550, 2000.

[32] M. A. Amer, "Mössbauer, infrared, and X-ray studies of Tidoped $\mathrm{CoCr}_{1.2} \mathrm{Fe}_{0.8} \mathrm{O}_{4}$ ferrites," Physica Status Solidi B, vol. 237, no. 2, pp. 459-471, 2003.

[33] M. El-Saadawy and M. M. Barakat, "Effect of jump length of electrons on the physical properties of Mn-doped $\mathrm{Co}_{0.6} \mathrm{Zn}_{0.4} \mathrm{Fe}_{2} \mathrm{O}_{4}$ ferrite," Journal of Magnetism and Magnetic Materials, vol. 213, no. 3, pp. 309-311, 2000.

[34] K. H. Rao, S. B. Raju, K. Aggarwal, and R. G. Mendiratta, "Effect of Cr impurity on the dc resistivity of Mn-Zn ferrites," Journal of Applied Physics, vol. 52, no. 3, pp. 1376-1379, 1981. 
[35] A. Globus, H. Pascard, and V. Cagan, "Distance between magnetic ions and fundamental properties in ferrites," Journal de Physique, vol. 38, no. C1, pp. 163-168, 1977.

[36] R. A. Brand, Laboratorium für Angewandte Physik, Universität Duisburg, Lotharstr 1, D-4100 Duisburg 1, Germany. 

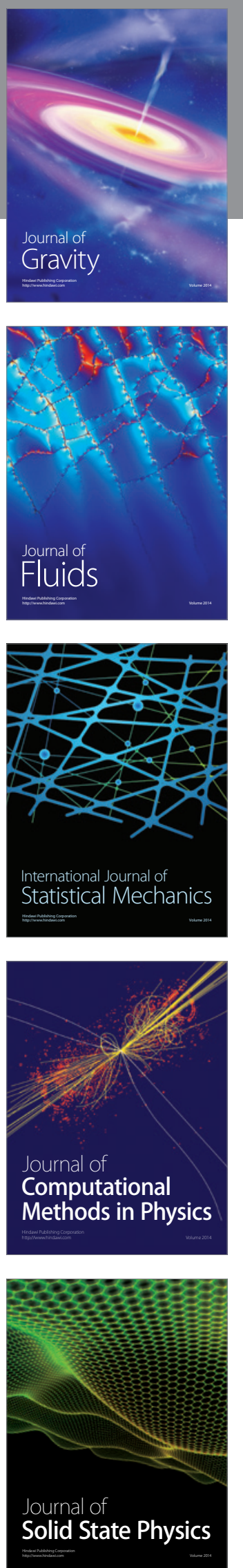

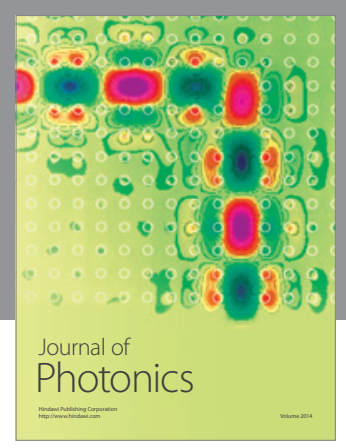

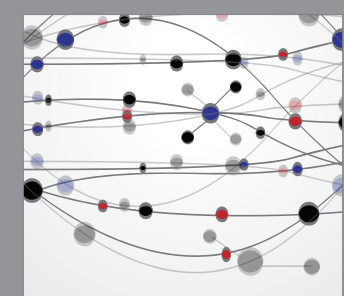

The Scientific World Journal
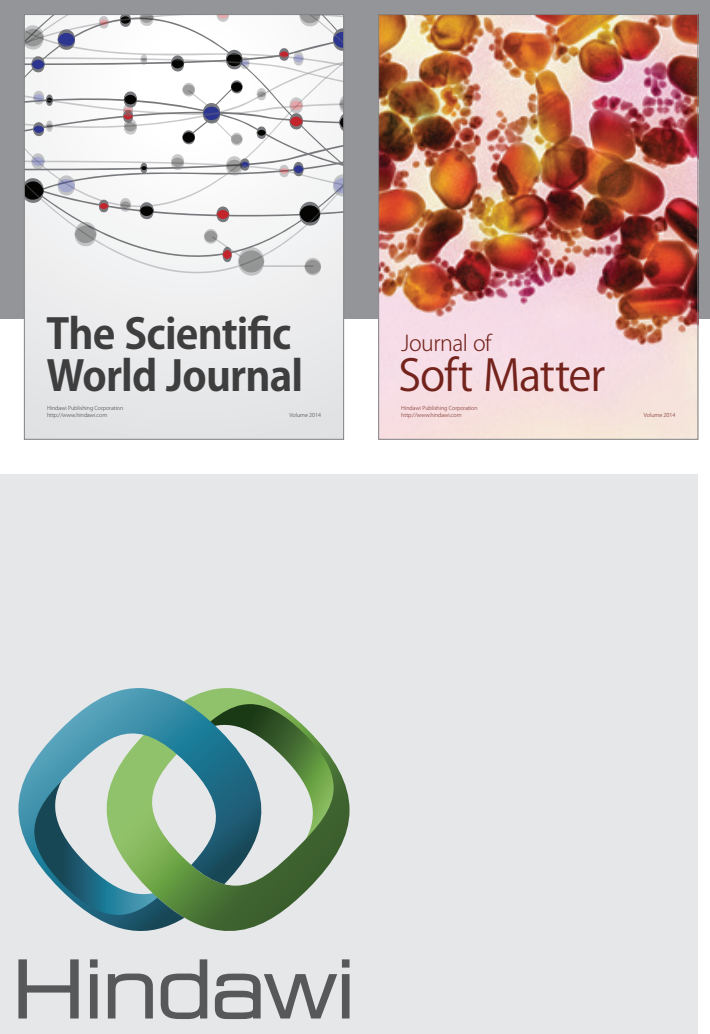

Submit your manuscripts at

http://www.hindawi.com
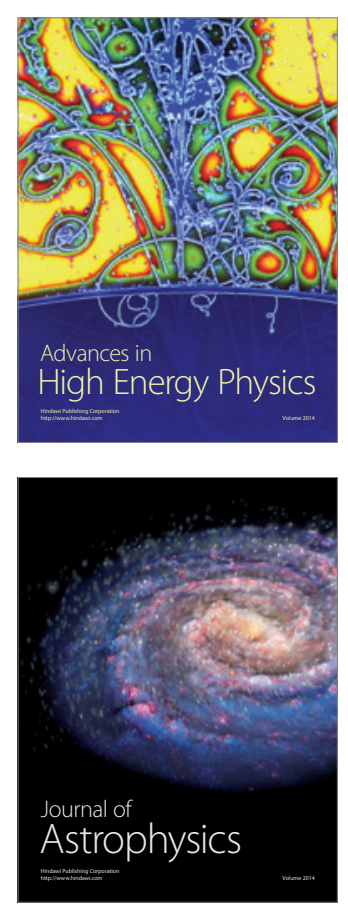
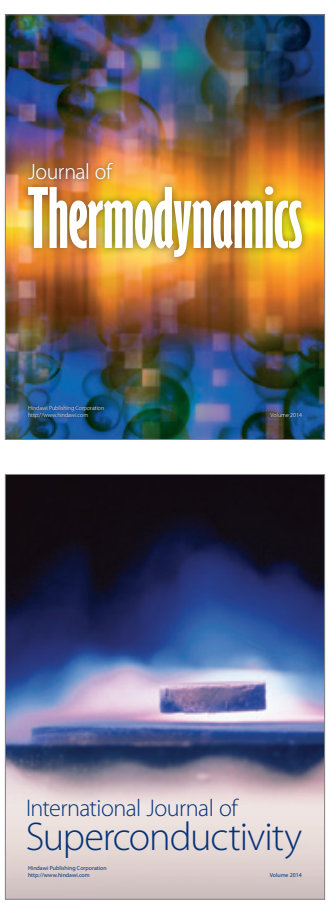
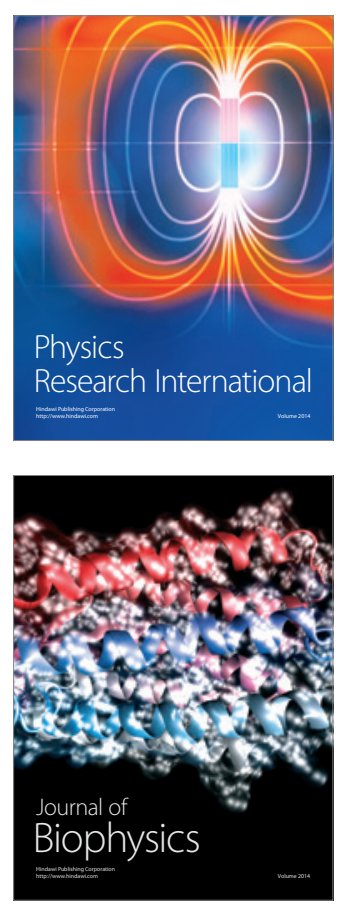
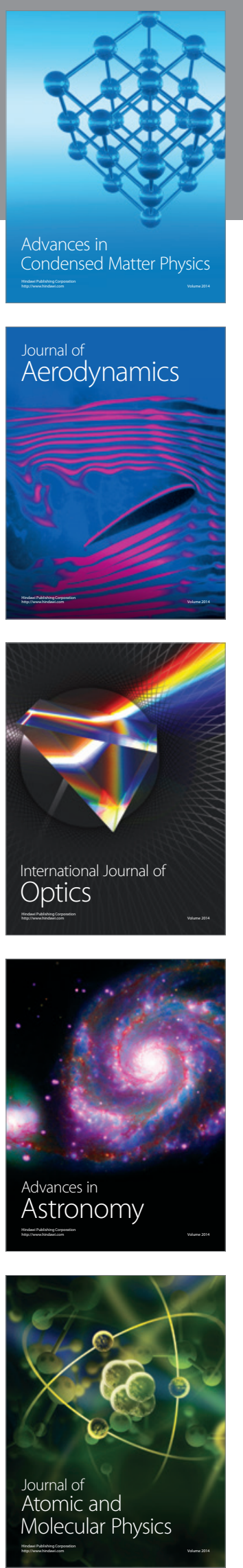